\title{
Presence of Glycopeptide-Encoding Plasmids in Enterococcal Isolates from Food and
} Humans in Denmark

\author{
Migura, Lourdes Garcia; Valenzuela, Antonio Jesus Sanchez; Jensen, Lars Bogø
}

Published in:

Foodborne Pathogens and Disease

Link to article, DOI:

10.1089/fpd.2011.0897

Publication date:

2011

Document Version

Publisher's PDF, also known as Version of record

Link back to DTU Orbit

Citation (APA):

Migura, L. G., Valenzuela, A. J. S., \& Jensen, L. B. (2011). Presence of Glycopeptide-Encoding Plasmids in Enterococcal Isolates from Food and Humans in Denmark. Foodborne Pathogens and Disease, 8(11), 11911197. https://doi.org/10.1089/fpd.2011.0897

\section{General rights}

Copyright and moral rights for the publications made accessible in the public portal are retained by the authors and/or other copyright owners and it is a condition of accessing publications that users recognise and abide by the legal requirements associated with these rights.

- Users may download and print one copy of any publication from the public portal for the purpose of private study or research.

- You may not further distribute the material or use it for any profit-making activity or commercial gain

- You may freely distribute the URL identifying the publication in the public portal 


\title{
Presence of Glycopeptide-Encoding Plasmids in Enterococcal Isolates from Food and Humans in Denmark
}

\author{
Lourdes Garcia-Migura,, ${ }^{1, \star}$ Antonio J. Sanchez-Valenzuela, ${ }^{2}$ and Lars Bogø Jensen ${ }^{1}$
}

\begin{abstract}
Enterococci and especially glycopeptides-resistant enterococci (GRE) are a growing concern due to their ability to cause infections in hospitals. Transmission of antimicrobial resistance between reservoirs such as animals, meat, and humans are in most cases linked to transmission of mobile genetic elements (MGE) such as plasmids and transposons. Presence of MGE was tested in all GRE isolated from food in Denmark in 2005-2007 including the first vanA mediated Enterococcus faecalis isolated from food. The ability of these plasmids to transfer and persist among enterococci was investigated using newly developed techniques for classification of plasmids. Replicons associated with sex pheromone-inducible plasmids were detected in all GR E. faecalis, whereas GR Enterococcus faecium contained plasmids known to be widely distributed among enterococci. vanA resistance is common in E. faecium isolates from meat and animals in Europe and is rarely found in E. faecalis. This article describes the first characterization of MGE from vanA mediated E. faecalis, thus linking this resistance genotype to pheromone responding plasmids.
\end{abstract}

\section{Introduction}

E NTEROCOCCI ARE WIDESPREAD in nature; however, for most enterococcal species, the predominant habitat is the gastrointestinal tract of animals and humans (Kuhn et al., 2005). Enterococci were previously considered to be merely commensal bacteria; however, Enterococcus faecalis and Enterococcus faecium have become the third- to fourth-most prevalent nosocomial pathogen worldwide (Werner et al., 2008).

Different clonal complexes adapted to humans have been identified among enterococci isolated from patients (Leavis et al., 2006). This may lower the survival potential of animal associated clones. Therefore, the most likely transmission of glycopeptide resistance from "farm to fork" appears to be horizontal transfer of mobile genetic elements (MGE) as reported in many studies (Leclercq et al., 1988; Heaton and Handwerger, 1995; Magi et al., 2003; Lim et al., 2006).

Acquired resistance to glycopeptides, in particular resistance mediated by van $A$ and vanB genes, are the most prevalent in Europe (Willems et al., 2005). These genes are often encoded by the transposons Tn1546 and Tn1549/Tn5382-like elements. Moreover, Tn1546 has frequently been found on conjugative plasmids that increase the mobility of the VanA-type resistance (Leclercq et al., 1988; Heaton and Handwerger, 1995; Magi et al., 2003; Lim et al., 2006; Sletvold et al., 2010).
Different conjugative transfer systems have been described for plasmids in enterococci. Plasmids belonging to the Inc18 group carrying glycopeptide resistance have been associated with transfer of vanA resistance gene to Staphylococcus aureus (Zhu et al., 2008). Recently, sex-pheromone plasmids, isolated from E. faecalis of human and poultry origin, have been associated with glycopeptide resistance (Tanimoto et al., 2005; Lim et al., 2006). A number of small peptides called pheromones (chromosomally encoded) are excreted into the medium by potential recipients producing a response in cells containing a sex-pheromone plasmid (potential donors). Transcription of a gene from the plasmid results in the production by the donor bacteria of agglutination substances that promote the attachment to recipient cells, thus causing a clumping reaction and high transfer rate (Dunny, 2007). For a broader plasmid classification, a new classification system was recently published for plasmid isolated from Gram-positive bacteria (Jensen et al., 2010). By the described method, prevalence of different rep-families can be determined using polymerase chain reaction (PCR) methods based on amplification of conserved sequences of rep-genes known to be found in enterococci and other Gram-positive bacteria.

Apart from classification of the plasmid backbone and its ability to proliferate and transfer, other elements are important for plasmid persistence. One of these is post segregation killing (PSK) systems. The PSK systems are regulatory

\footnotetext{
${ }^{1}$ National Food Institute, Division of Microbiology and Risk Assessment, Antimicrobial Resistance Unit, Technical University of Denmark Lyngby, Denmark.

${ }^{2}$ Microbiology Area, Department of Health Science, University of Jaen, Jaen, Spain.

*Current address: Edifici CReSA, Universidad Autónoma de Barcelona, Barcelona, Spain.
} 
systems consisting of a sense and antisense RNA where the antisense RNA's half life is reduced compared with the sense, thereby activating expression of a toxic protein encoded by the sense RNA in plasmid-free cells (Gerdes et al., 2005). This prevents survival of plasmid-free progeny. Presence of a PSK system on plasmids will enhance the success for stable maintenance of these plasmids in their host.

Prevalence of glycopeptides-resistant enterococci (GRE) in food animals in Denmark has been screened continuously since 1995 (Danish Integrated Antimicrobial Resistance Monitoring and Research Program, DANMAP). Recently, the first GRE were detected in food in Denmark. Among these were the first ever nonhuman detected glycopeptide-resistant vanA mediated E. faecalis (Agersø et al., 2008). After this finding, we have characterized the transposons mediating resistance to glycopeptide and the plasmids encoding this transposon using the novel plasmid classification system (Jensen et al., 2010), tested the presence of PSK, and studied for possible co-transfer of antimicrobial resistance.

\section{Materials and Methods}

\section{Isolation and identification of antimicrobial resistant enterococci}

Enterococci were isolated without selective enrichment and identified as previously described (DANMAP, 2006). A total of nine GRE strains, including eight E. faecalis and one E. faecium, were selected for the study (Table 1 ). They comprised all GRE isolated from food in Denmark during 2005-2007 (six GRE isolated from turkey meat imported to Denmark) and three strains of human origin, both community acquired $(n=2)$, and a hospitalized patient isolated between 2003 and 2006. All selected isolates were tested for resistance to ampicillin, avilamycin, chloramphenicol, daptomycin, erythromycin, gentamicin, kanamycin, linezolid, moxifloxacin, penicillin, salinomycin, streptomycin, quinupristin/dalfopristin, tetracycline, tigercycline, and vancomycin using micro broth dilution and minimum inhibitory concentrations (MIC) as previously described (DANMAP, 2006). The strains and their relevant characteristics are summarized in Table 1.

\section{Genetic characterization}

Antimicrobial resistance genes. All isolates were screened for the presence of antimicrobial resistance genes to detected phenotypes. The isolates and their corresponding transconjugants were also screened for the presence of vanX and the point mutations G to T at position 8234 (Jensen et al., 1998). Donors and transconjugants were tested by PCR for the presence of Tn916 associated with transferability of tetracycline and tet $(\mathrm{K})$, tet $(\mathrm{L})$, tet $(\mathrm{M})$, tet $(\mathrm{O})$, and tet $(\mathrm{S})$ as previously described (Aarestrup et al., 2000). Isolates were examined for the presence of the following resistance genes: $\operatorname{erm}(\mathrm{B})$ (Jensen et al., 1999), vat(D) and $\operatorname{vat}(\mathrm{E})$ (Jensen et al., 2002), aphA-3, and cat (Aarestrup et al., 2000).

Transposon characterization (Tn1546). A previously described long-PCR (L-PCR) method was used to detect the inverted repeats of Tn1546 (Palepou et al., 1998). Strains not producing amplicons with L-PCR were characterized using overlapping PCR (Woodford et al., 1998). Further, the integration point of the transposon was assessed rather into a streptomycin resistance gene or into an Inc18-like plasmid as previously described (Garcia-Migura et al., 2008).

\section{Transferability of resistance}

Conjugation of glycopeptide resistance from the nine isolates to two well-known rifampicin and fusidic acid resistant recipient strains (E. faecium $64 / 3$ and E. faecalis $\mathrm{JH} 2-2$ ) was performed using filter-mating as previously described (Clewell et al., 1985).

\section{Plasmid characterization}

Replicon typing. Donors and transconjugants were analyzed by multiplex-PCR for 19 different plasmid replicons typical of Gram-positive bacteria (Jensen et al., 2010). Representative amplicons were purified and sequenced. Editing and alignment of DNA sequences was performed using Vector NTI advance 10.

Occurrence of toxin-antitoxin systems. All isolates were examined by PCR for the presence of axe-txe and the two versions of $\omega-\varepsilon-\zeta$ toxin-antitoxin systems responsible for plasmid maintenance as previously described (Sletvold et al., 2008).

S1 nuclease pulsed-field gel electrophoresis and Southern-blot hybridization. Four representatives were selected based on the plasmid profiling, three E. faecalis and the E. faecium, their corresponding transconjugants were selected, and plasmid location of vanX and rep genes was assessed by the method of Barton hybridizing S1 nuclease-digested genomic DNA (Barton et al., 1995). Digoxigenin-labeled probes for vanX and repA of pAD1 were prepared and labeled with DIG DNA Labelling Mix (Roche). Hybridization and colorimetric detection were performed as described by the manufacturer (Roche).

\section{Results}

\section{Phenotypic resistance}

A total of nine GRE were analyzed in this study consisting of eight $E$. faecalis and one E. faecium. All isolates were resistant to vancomycin (MIC $\geq 32 \mathrm{mg} / \mathrm{L}$ ), erythromycin (MIC $\geq 16 \mathrm{mg} / \mathrm{L}$ ), and tetracycline (MIC $\geq 16 \mathrm{mg} / \mathrm{L} ;$ Table 1 ). The $E$. faecium strain and the E. faecalis 769374.02 were also resistant to kanamycin (MIC $\geq 2048 \mathrm{mg} / \mathrm{L}$ ) and streptomycin (MIC $\geq 2048 \mathrm{mg} / \mathrm{L}$ ). In addition, E. faecalis 769374.02 was resistant to chloramphenicol (MIC $\geq 32 \mathrm{mg} / \mathrm{L}$ ).

\section{Genetic characterization}

Antimicrobial resistance genes. All GRE tested positive for vanX, thus indicating the presence of Tn1546. DdeI digestion of vanX PCR amplicons showed the three predicted bands of the wild-type vanX gene in all isolates. All isolates were positive for Tn916, tet(M), and tet(L) except for E. faecium 785864.21, which was negative for Tn916 and tet(M) but positive for tet $(\mathrm{L})$. E. faecium 785864.21 was also able to transfer this gene to E. faecium 64/3. None of the isolates nor the transconjugants from E. faecalis 9677 tested positive for tet $(\mathrm{K})$, tet $(\mathrm{O})$, or tet $(\mathrm{S})$. All donors and transconjugants contained the $\operatorname{erm}(\mathrm{B})$ gene, whereas none of them tested positive for vat(D) or vat(E). The kanamycin-resistant strains, E. faecium 


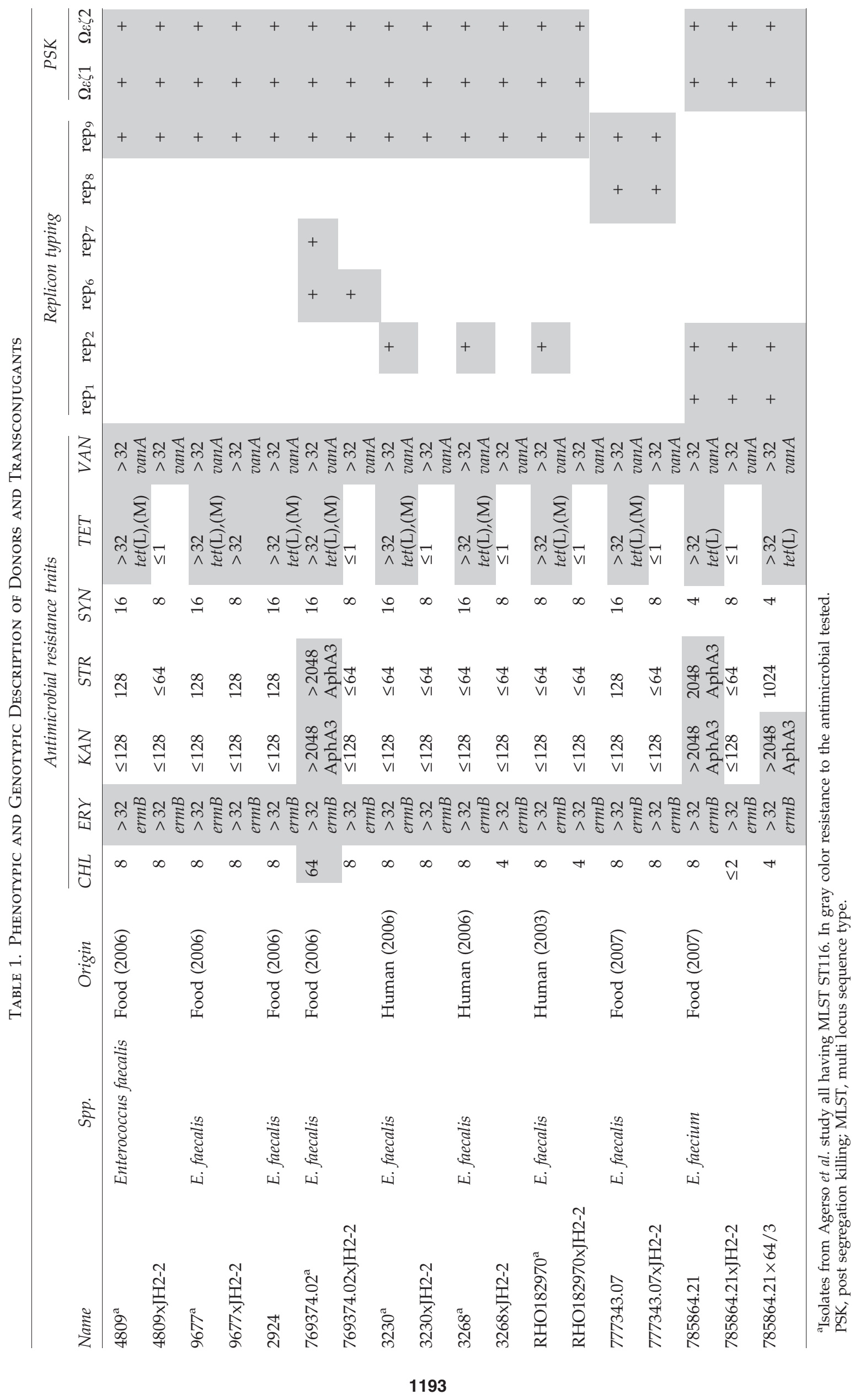


785864.21 and E. faecalis 769374.02 were positive for $a p h A-3$ gene. E. faecium 785864.21 was able to transfer aphA-3 gene to the E. faecium 64/3 recipient strains, whereas E. faecalis 769374.02 was unable to transfer this gene. None of the strains tested positive for cat.

Transposon characterization (Tn1546). Transposon characterization by L-PCR revealed the presence of the wildtype transposon in all E. faecalis strains $(n=8)$, whereas $E$. faecium did not yield an amplicon by L-PCR. The PCR targeting both ends of the transposon showed that E. faecium lacked both inverted repeats of Tn1546. Further, the first part of the Tn1546 was substituted with insertion of an IS3-like element linked to an IS1216V . All isolates tested negative by PCR for previously published integration points (GarciaMigura et al., 2008).

\section{Transferability of glycopeptide resistance}

The results of the filter mating experiments showed that eight out of nine potential donors were able to transfer the glycopeptide resistance genes (Table 1). However, seven of the E. faecalis strains could only transfer the van A genes to the recipient E. faecalis JH2-2, whereas E. faecium 785864.21 was able to mobilize the glycopeptide resistance genes to both recipients. All donors concurrently transferred resistance to macrolides. Further, co-transfer of kanamycin and tetracycline resistance was also observed from E. faecium (Table 1).

\section{Plasmid characterization}

Replicon typing. All E. faecalis yielded an amplicon for the rep9 family of plasmids, similar to sex pheromone pAD1 plasmid. Sequencing of the obtained amplicons showed $100 \%$ identity to an internal region of the repA gene of pAD1. Analysis of the plasmid content by multiplex-PCR differentiated the nine donors into five groups: (i) contained three $E$. faecalis that were positive for rep9. (ii) contained three E. faecalis with positive amplicons for both rep9 and rep2 (pRE25like). (iii) E. faecalis 769374.02 that yielded amplicons for rep9, rep6 (pS86-like), and rep7 (pS194-like). (iv) E. faecalis 777343.07 that gave positive amplicons for rep8 (pAM373-like) and rep9. (v) E. faecium 785864.21 that contained replicons for rep1 (pIP501-like) and rep2.

Plasmids containing a pAD1-like replicon were mobilized from seven out of eight potential donors to E. faecalis JH2-2 when selecting for glycopeptide. Further, plasmids from rep 6 and $\mathrm{rep}_{8}$ groups were also transferred to the recipient strains, corresponding to a small cryptic theta replicating plasmid and a sex-pheromone responding plasmid, respectively. Interestingly, strains of $E$. faecalis containing replicons from rep 2 were not able to transfer them to E. faecalis JH2-2, whereas E. faecium was able to transfer them to both species used as recipients.

PSK systems. With the exception of E. faecalis 777343.07, all isolates and transconjugants yielded amplicons for both versions of one of the two PSK system tested for $(\Omega \varepsilon \zeta 1$ and $\Omega \varepsilon \zeta 2)$. The axe/txe system was not detected.

S1 nuclease digestion. Strains representing four of the five defined plasmid profiles based on replicon typing were further investigated. The S1 digestion of the plasmid content of three selected E. faecalis donors (Fig. 1) revealed the pres-

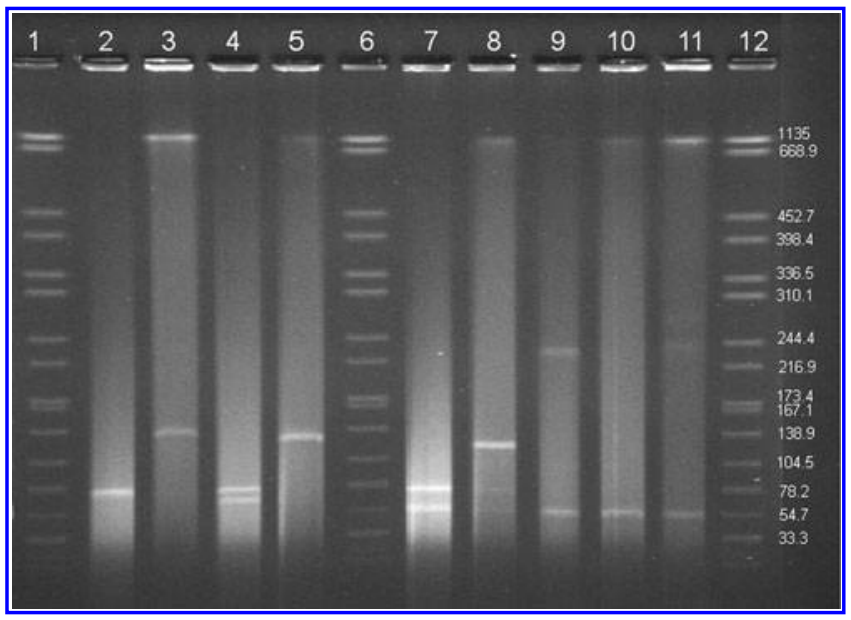

FIG. 1. S1 nuclease gel-illustrating plasmid content from donors and recipients. Notice in lane 3, 5, and 8 which represent the plasmid content of three Enterococcus faecalis transconjugants the presence of high-molecular-weight plasmids that are not present in the donor strains. Lane 1,6, and 12 show XbaI digestion of Salmonella branderup. Lane 2 E. faecalis 9677 donor, lane $3 \mathrm{E}$. faecalis JH2- $\times 9677$ (transconjugants), lane 4 E. faecalis 3268, lane 5 E. faecalis JH2-2×3268 (transconjugants), lane 7 E. faecalis 777343.07 , lane 8 E. faecalis $\mathrm{JH} 2-2 \times 777343.07$ (transconjugants), lane $9 \mathrm{E}$. faecium 785864.21, lane 10 E. faecalis JH2-2 $\times 785864.21$ (transconjugants), lane 11 E. faecium $64 / 3 \times 785864.21$ (transconjugants).

ence of a common plasmid of approximately $70 \mathrm{~Kb}$ hybridizing to the repA probe of pAD1 plasmid and the vanX gene probe (data not shown). E. faecalis 3268 and E. faecalis 777343.07 contained extra plasmids of approximately 60 and $54 \mathrm{~Kb}$, respectively. Further, S1 nuclease digestion of the corresponding transconjugants detected the presence of highmolecular-weight plasmids $(120-140 \mathrm{~kb})$ not found on the donor strains (Fig. 1). E. faecium 785864.21 harbored a plasmid of approximately $240 \mathrm{~Kb}$ and a smaller plasmid of $54 \mathrm{~Kb}$ that hybridized to the vanX gene. A plasmid of similar size was detected in transconjugants of both E. faecalis $\mathrm{JH} 2-2$ and $E$. faecium $64 / 3$

\section{Discussion}

This article describes the genetic characterization of plasmids isolated from GRE of food and human origin in Denmark. Using a newly designed plasmid classification system, the presence of the 19 defined rep-families was investigated. Most tested enterococci contained more than one plasmid. The E. faecalis strains harbored plasmids belonging to the rep, family. This rep family was absent in the E. faecium strain in agreement with previous results (Jensen et al., 2010; Rosvoll et al., 2010). Sequences of the obtained amplicons were identical to the repA of pAD1, and S1 nuclease digestion revealed the presence of a common plasmid of approximately $70 \mathrm{~kb}$ in both, E. faecalis of humans and food origin, which suggests transmission of MGE between these two reservoirs. Further, this plasmid could only be transferred by conjugation into the E. faecalis JH2-2 recipient strain, demonstrating the narrow host range specificity of these plasmids. Both, plasmids from donors and transconjugants hybridized to the rep and vanX, proved a linkage between sex-pheromone inducible plasmids 
and glycopeptide resistance. However, during conjugation, the size of the plasmid changed from $70 \mathrm{~kb}$ to approximately 120 $140 \mathrm{~kb}$ (Fig. 1, lane 3, 5, and 8), thus suggesting plasticity of the investigated plasmids. Whether this change in size is a result of incomplete resolvation (approximately double size of the donor plasmid) or the acquisition of previously encoded chromosomal DNA of the donor cannot be evaluated in the present experimental setup. Similar changes in plasmid size during conjugation have been indicated for enterococci in other studies (Guardabassi and Dalsgaard, 2004; Coque, personal communication). Plasmids are very dynamic structures, and these events demonstrate the plasticity of the MGE and the rearrangements that may occur during conjugation processes. Presence of glycopeptide encoded in sex-pheromone plasmids have been detected in Asia in enterococci from production animals (Tanimoto et al., 2005; Lim et al., 2006; Getachew et al., 2009; Harada et al., 2010) but only described in a few studies in Europe (Sabia et al., 2007; Haenni et al., 2009; Biendo et al., 2010). Further, since a unique plasmid was detected in the transconjugants, this plasmid presumable also co-transferred the $\operatorname{erm}(\mathrm{B})$ gene.

In agreement with previous studies (Manson et al., 2003), no linkage between vanA and tet( $\mathrm{M})$ could be demonstrated while co-transfer of tet $(\mathrm{L})$ was encountered. All transconjugants tested negative for the presence of Tn916, which indicate a chromosomal location of this transposon. It was interesting to find two mechanisms of tetracycline resistance, tet $(\mathrm{L})$ and tet $(\mathrm{M})$, in the same isolates. Further, E. faecalis 9677 JH2-2 transconjugant tested negative for all tet genes investigated, thus indicating the presence of a mechanism of tetracycline resistance not tested in this experimental setup or mutations in the target sequence of the primers used for screening. It is intriguing to understand the reason for harboring so many resistance genes for the same antimicrobial, but this could probably reflect the environmental pressures previously imposed on these clones.

Among these genetically related GR E. faecalis of different origin (food retail, humans in the community, and hospital bacteraemia), the same wild-type Tn1546 was found to be associated with the same MGE. Seven out of eight potential E. faecalis donors transferred glycopeptide resistance to E. faecalis JH2-2 by filter mating. Despite having similar gene content in terms of rep genes and PSK systems, E. faecalis 2924 did not mobilize the vanA gene. Since mobilization of plasmids is driven by the mob genes, perhaps mutations in the sequence of this gene have impaired the transferability of the plasmid.

E. faecium 785864.21 showed the presence of an IS3 element followed by an IS1216 V upstream of the transposon. These insertion elements appeared to cause the deletion of ORF1 (transposase), which should affect the dissemination of Tn1546. Similar deletions and integrations have been previously found among GR E. faecium of porcine origin in Denmark, but all porcine linked Tn1546 have a mutation in vanX (Jensen et al., 1998) not found in the tested E. faecium. Conjugation experiments followed by plasmid characterization demonstrated the successful transfer of glycopeptide resistance to both, E. faecalis $\mathrm{JH} 2-2$ and E. faecium 64/3, most likely integrated in an Inc18-like plasmid, belonging to the rep 2 family, of approximately $57 \mathrm{~Kb}$. This family of plasmids is widely disseminated (Jensen et al., 2010; Rosvoll et al., 2010) and has been described to be involved in the emergence of the first vancomycin resistance $S$. aureus case (Zhu et al., 2008). In addition, mobilization of a highmolecular-weight plasmid of approximately $240 \mathrm{~kb}$ and co- transfer of other resistance traits such as kanamycin (aphA-3), streptomycin, and tetracycline [tet $(\mathrm{L})]$ was also observed.

PSK systems secure the stable inheritance of plasmids during cell division by killing or impairing the growth of cells that have lost the plasmid (Gerdes et al., 2005). All E. faecalis and transconjugants contained $\omega-\varepsilon-\zeta$ PSK systems. Even though the presence of PSK systems could decrease the growth rate of a bacterial clone by killing the plasmid-free part of the population, clones containing them will not be able to lose the plasmids, thereby ensuring proliferation of the plasmids in the enterococcal population.

In this study, vanA E. faecalis were isolated from food imported into Demark and from isolates of hospitalized humans. All GRE of food origin were obtained from turkey meat imported from Germany during 2005-2007. It is interesting to notice that the antimicrobial avoparcin was banned in Europe in 1999. However, glycopeptide resistance appears to still be present at low levels in production animals (DANMAP, 2006; Sorum et al., 2006), and GR E. faecalis have been isolated in low prevalence in food animals in Europe (Sabia et al., 2007; Haenni et al., 2009; Biendo et al., 2010). Macrolides are extensively used for animal production and also for the treatment of infections in humans. Co-selection and persistence of GRE by the use of macrolide is suggested by the successful cotransfer of glycopeptide and macrolide resistance in this experimental setting. In addition, the prevalence of PSK will uphold the presence of glycopeptide resistance.

This GRE collection contained all GRE isolated from food in Denmark during 2005-2007 and three human GRE faecalis, two from 2006 and the first GR E. faecalis RHO182970 from human origin isolated in Denmark dated from 2003 (Agersø et al., 2008). Plasmid characterization has demonstrated the presence of a plasmid of identical size belonging to the rep 9 group among $E$. faecalis of human origin and imported food. Even though the first isolated GR E. faecalis of human origin originated from 2003 and the food isolates were obtained between 2005 and 2007, results presented here indicate prevalence and persistence of these plasmids and transmission between the food and the human reservoir. Therefore, food available in Denmark is still a source of GRE that may be able to transfer glycopeptide resistance to human isolates.

\section{Acknowledgments}

The study was supported by the European Union Sixth Framework Programme "Approaches to Control multiresistant Enterococci: Studies on molecular ecology, horizontal gene transfer, fitness and prevention" under contract LSHECT-2007-037410. Antonio received a grant from the Health Institute Carlos III (Spain). The authors gratefully acknowledge Jacob Dyring Jensen at the DTU-FOOD for his technical support.

\section{Disclosure Statement}

No competing financial interests exist.

\section{References}

Aarestrup FM, Agerso Y, Gerner-Smidt P, Madsen M, and Jensen LB. Comparison of antimicrobial resistance phenotypes and resistance genes in Enterococcus faecalis and Enterococcus faecium from humans in the community, broilers, and pigs in Denmark. Diagn Microbiol Infect Dis 2000;37:127-137. 
Agersø Y, Lester CH, Porsbo LJ, Orsted I, Emborg HD, et al. Vancomycin-resistant Enterococcus faecalis isolates from a Danish patient and two healthy human volunteers are possibly related to isolates from imported turkey meat. I Antimicrob Chemother 2008;62:844-845.

Barton BM, Harding GP, and Zuccarelli AJ. A general method for detecting and sizing large plasmids. Anal Biochem 1995; 226:235-240.

Biendo M, Adjide C, Castelain S, Belmekki M, Rousseau F, Slama M, Ganry O, Schmit JL, and Eb F. Molecular characterization of glycopeptide-resistant enterococci from hospitals of the Picardy region (France). Int J Microbiol 2010;150464.

Clewell DB, An FY, White BA, and Gawron-Burke C. Streptococcus faecalis sex pheromone (cAM373) also produced by Staphylococcus aureus and identification of a conjugative transposon (Tn918). J Bacteriol 1985;162: 1212-1220.

[DANMAP] Danish Integrated Antimicrobial Resistance Monitoring and Research Program. Use of antimicrobial agents and occurrence of antimicrobial resistance in bacteria from food animals, foods and humans in Denmark. 2006. ISSN 1600-2032.

Dunny GM. The peptide pheromone-inducible conjugation system of Enterococcus faecalis plasmid pCF10: cell-cell signalling, gene transfer, complexity and evolution. Philos Trans

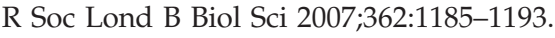

Garcia-Migura L, Hasman H, Svendsen C, and Jensen LB. Relevance of hot spots in the evolution and transmission of Tn1546 in glycopeptide-resistant Enterococcus faecium (GREF) from broiler origin. J Antimicrob Chemother 2008;62:681-687.

Gerdes K, Christensen SK, and Lobner-Olesen A. Prokaryotic toxin-antitoxin stress response loci. Nat Rev Microbiol 2005; 3:371-382.

Getachew YM, Hassan L, Zakaria Z, Saleha AA, Kamaruddin MI, and Che Zalina, MZ. Characterization of vancomycinresistant Enterococcus isolates from broilers in Selangor, Malaysia. Trop Biomed 2009;26:280-288.

Guardabassi L and Dalsgaard A. Occurrence, structure, and mobility of Tn1546-like elements in environmental isolates of vancomycin-resistant enterococci. Appl Environ Microbiol 2004;70:984-990.

Haenni M, Saras E, Chatre P, Meunier D, Martin S, Lepage G, Menard MF, Lebreton P, Rambaud T, and Madec JY. vanA in Enterococcus faecium, Enterococcus faecalis and Enterococcus casseliflavus detected in French cattle. Foodborne Pathog Dis 2009;6:1107-1111.

Harada T, Kanki M, Kawai T, Taguchi M, Asao T, and Kumeda Y. Isolation of VanA-type vancomycin resistant Enterococcus strains from domestic poultry products with enrichment by incubation in buffered peptone water at $42^{\circ} \mathrm{C}$. Appl Environ Microbiol 2010;76:5317-5320.

Heaton MP and Handwerger S. Conjugative mobilization of a vancomycin resistance plasmid by a putative Enterococcus faecium sex pheromone response plasmid. Microb Drug Resist 1995;1:177-183.

Jensen LB. Differences in the occurrence of two base pair variants of Tn1546 from vancomycin-resistant enterococci from humans, pigs, and poultry. Antimicrob Agents Chemother 1998;42:2463-2464.

Jensen LB, Agerso Y, and Sengeløv G. Presence of erm genes among macrolide-resistant Gram-positive bacteria isolated from Danish farm soil. Environ Int 2002;28:487-491.

Jensen LB, Ahrens P, Dons L, Jones RN, Hammerum AM, and Aarestrup FM. Molecular analysis of Tn1546 in Enterococcus faecium isolated from animals and humans. J Clin Microbiol 1998;36:437-442.
Jensen LB, Frimodt-Moller N, and Aarestrup FM. Presence of erm gene classes in Gram-positive bacteria of animal and human origin in Denmark. FEMS Microbiol Lett 1999;170: 151-158.

Jensen LB, Garcia-Migura L, Sanchez-Valenzuela AJ, Løhr M, Hasman H, and Aarestrup FM. A classification system for plasmids from enterococci and other Gram-positive bacteria. I Microbiol Methods 2010;80:25-43.

Kuhn I, Iversen A, Finn M, Greko C, Burman L, Blanch AR, et al. Occurrence and relatedness of vancomycin-resistant enterococci in animals, humans, and the environment in different European regions. Appl Environ Microbiol 2005;71: 5383-5390.

Leavis HL, Bonten MJ, and Willems RJ. Identification of highrisk enterococcal clonal complexes: global dispersion and antibiotic resistance. Curr Opin Microbiol 2006;9:454-460.

Leclercq R, Derlot E, Duval J, and Courvalin P. Plasmidmediated resistance to vancomycin and teicoplanin in Enterococcus faecium. N Engl J Med 1988;319:157-161.

Lim SK, Tanimoto K, Tomita $\mathrm{H}$, and Ike Y. Pheromoneresponsive conjugative vancomycin resistance plasmids in Enterococcus faecalis isolates from humans and chicken feces. Appl Environ Microbiol 2006;72:6544-6553.

Magi G, Capretti R, Paoletti C, Pietrella M, Ferrante L, and Biavasco F. Presence of a vanA-carrying pheromone response plasmid (pBRG1) in a clinical isolate of Enterococcus faecium. Antimicrob Agents Chemother 2003;47:1571-1576.

Manson JM, Keis S, Smith JMB, and Cook GMJ. Characterization of a vancomycin-resistant Enterococcus faecalis (VREF) isolate from a dog with mastitis: further evidence of a clonal lineage of VREF in New Zealand. J Clinical Micro 2003;41: 3331-3333.

Palepou MF, Adebiyi AM, Tremlett CH, Jensen LB, and Woodford N. Molecular analysis of diverse elements mediating VanA glycopeptide resistance in enterococci. J Antimicrob Chemother 1998;42:605-612.

Rosvoll TCS, Pedersen T, Sletvold H, Johnsen PJ, Sollid JE, Simonsen GS, Jensen LB, Nielsen KM, and Sundsfjord A. FEMS Immunol Med Microbiol 2010;58:254-268.

Sabia C, de Niederhaüsern S, Guerrieri E, Messi P, Anacarso I, Manicardi G, and Bondi M. Detection of bacteriocin production and virulence trait in vancomycin-resistant enterococci of different sources. I Appl Microbiol 2007;104:970-979.

Sletvold H, Johnsen PJ, Hamre I, Simonsen GS, Sundsfjord A, and Nielsen KM. Complete sequence of Enterococcus faecium pVEF3 and the detection of an omega-epsilon-zeta toxinantitoxin module and an ABC transporter. Plasmid 2008; 60:75-85.

Sletvold H, Johnsen PJ, Wikmark OG, Simonsen GS, Sundsfijord A, and Nielsen KM. Tn1546 is part of a larger plasmidencoded genetic unit horizontally disseminated among clonal Enterococcus faecium lineages. I. Antimicrob Chemother 2010; 65:1894-1906.

Sorum M, Johnsen PJ, Aasnes B, Rosvoll T, Kruse H, Sundsfjord A, et al. Prevalence, persistence, and molecular characterization of glycopeptide-resistant enterococci in Norwegian poultry and poultry farmers 3 to 8 years after the ban on avoparcin. Appl Environ Microbiol 2006;72:516-521.

Tanimoto K, Nomura T, Hamatani H, Xiao YH, and Ike Y. A vancomycin-dependent VanA-type Enterococcus faecalis strain isolated in Japan from chicken imported from China. Lett Appl Microbiol 2005;41:157-162.

Werner G, Coque TM, Hammerum AM, Hope R, Hryniewicz W, Johnson A, et al. Emergence and spread of vancomycin 
resistance among enterococci in Europe. Euro Surveill 2008;13:pii: 19046.

Willems RJ, Top J, van Santen M, Robinson DA, Coque TM, Baquero $\mathrm{F}$, et al. Global spread of vancomycin-resistant Enterococcus faecium from distinct nosocomial genetic complex. Emerg Infect Dis 2005;11:821-828.

Woodford N, Adebiyi AM, Palepou MF, and Cookson BD. Diversity of VanA glycopeptide resistance elements in enterococci from humans and nonhuman sources. Antimicrob Agents Chemother 1998;42:502-508.

Zhu W, Clark NC, McDougal LK, Hageman J, McDonald LC, and Patel JB. Vancomycin-resistant Staphylococcus aureus iso- lates associated with Inc18-Like vanA plasmids in Michigan. Antimicrob Agents Chemother 2008;52:452-457.

Address correspondence to: Lourdes Garcia-Migura, Ph.D. Edifici CReSA Universidad Autónoma de Barcelona 08193 Barcelona Spain

E-mail: lourdes.migura@cresa.uab.cat 
